American Journal of Environmental Sciences 8 (3): 212-219, 2012

ISSN 1553-345X

(C) 2012 Science Publications

\title{
Ecological Sanitation in Morocco Promotion of the Urine-Diversion Dehydration Toilets-Case of Dayet Ifrah
}

\author{
${ }^{1}$ Youssef Abarghaz, ${ }^{2} \mathrm{M}$. Mustapha Mahi, ${ }^{3}$ Mme Christine Werner, \\ ${ }^{1}$ Najib Bendaou and ${ }^{4}$ Mohammed Fekhaoui \\ ${ }^{1}$ Faculty of Science, Mohammed V-Agdal University Rabat, Morocco \\ ${ }^{2}$ Institut International de l'Eau et de l'Assainissement, Morocco \\ ${ }^{3}$ Department of Technical Adviser at the GIZ, Morocco \\ ${ }^{4}$ Scientific Institute Mohammed V-Agdal University Rabat, Morocco
}

\begin{abstract}
Problem statement: Most of people in rural areas in Morocco don't have adequate systems of collection, evacuation and transport of black and gray water. They simply defecate in nature. There is a huge demand, which cannot possibly be met by conventional sanitation systems due to the enormous costs of the pipe network, lack of water and serious environmental drawbacks in order to avoid the disadvantages of conventional wastewater systems. For this reason, we have thought to promote ecological sanitation, or "ecosan" for short, that recognizes human excreta and water from households not as a waste but as resources that can be recovered, treated where necessary and safely used again. Ecosan is a philosophy which houses a multitude of different technologies applied in ecological sanitation projects such as Urine Diversion Dehydration Toilets (UDDT). Approach: The scope of the study was to highlight the ecosan promotion strategies and policies for its adoption by the future ecosan users in Morocco and to show that the development of ecosan pilot systems adapted to the sociocultural context of Morocco is possible and can be used as model for rural areas. Ecosan systems studied had been implemented in a small rural area in Morocco called "Dayet Ifrah". But, it's necessary at the beginning to sensitize people in Dayet Ifrah and to convince to adopt and accept urine diversion dehydration toilets. Marketing has been more successful than anything else in changing the behavior of people when they can see direct personal benefits. Choosing a (social) marketing approach means that the attractiveness of the product is one important factor. That was what happened in 2009. Results: After this phase of sensitizing, results reveal that the households were convinced of the benefits these infrastructures afford them. Ecosan reduces the health risks related to sanitation, contaminated water and waste, prevents the pollution of surface and groundwater, prevents the degradation of soil fertility and optimizes the management of nutrients and water resources. Conclusion: The users are satisfied with the ecosan approach to cleanse their wastewater. Our work shows that ecosan can succeed in very poor populations. It is particularly relevant as locomotors of agricultural economics.
\end{abstract}

Key words: Ecological sanitation, rural areas, drinking water, sanitation systems, urine diversion, wooden lid, local authority, ecosan pilot project

\section{INTRODUCTION}

According to the household survey that I carried out in 2009, thanks to the support of the local authorities and associations, the households at Dayet Ifrah village agree to quickly adopt the ecosan approach in which faeces and urine are stored and then re-used as manure for agriculture. The nutrients contained in the urine are not lost during the process of collection and storage and the urine fertilizing effects are as good as those of chemical fertilizers (Drangert et al., 1997).
Nutrients included were nitrogen $(\mathrm{N})$, phosphorus (P) and kalium (K). The characteristics $(\mathrm{N}, \mathrm{P}, \mathrm{K}$ contents) of faeces and urine were based on former studies (Tchobanoglous et al., 2000; Wang and Nie, 2001; Lens et al., 2001; Werner et al., 2004).

The first ecosan system promoted in 2009 in Morocco especially in Dayet Ifrah near Ifrane (Latitude of $33^{\circ} 34^{\circ} \mathrm{N}$, longitude of $4^{\circ} 55^{\circ} \mathrm{W}$ and Altitude of $1665 \mathrm{~m}$ ) city was the UDDT (Fig. 1).

Corresponding Author: Youssef Abarghaz, Faculty of Science, Mohammed V-Agdal University Rabat, Morocco 


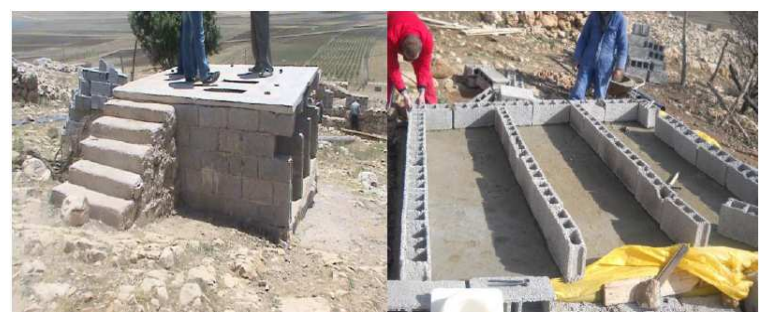

Fig. 1: 1st UDDT in Morocco built in December 2009

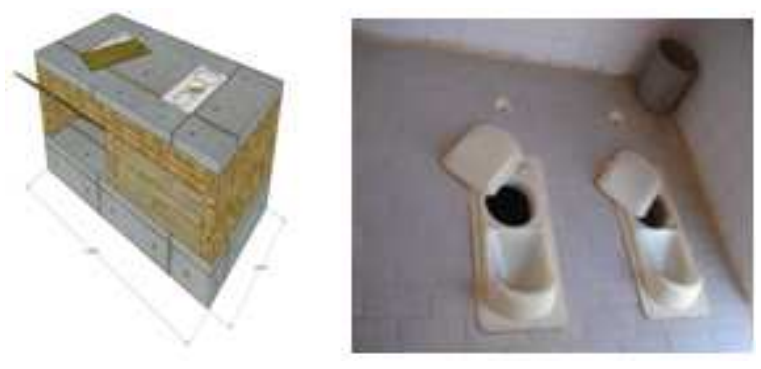

Fig. 2: Two pits functioning alternatively

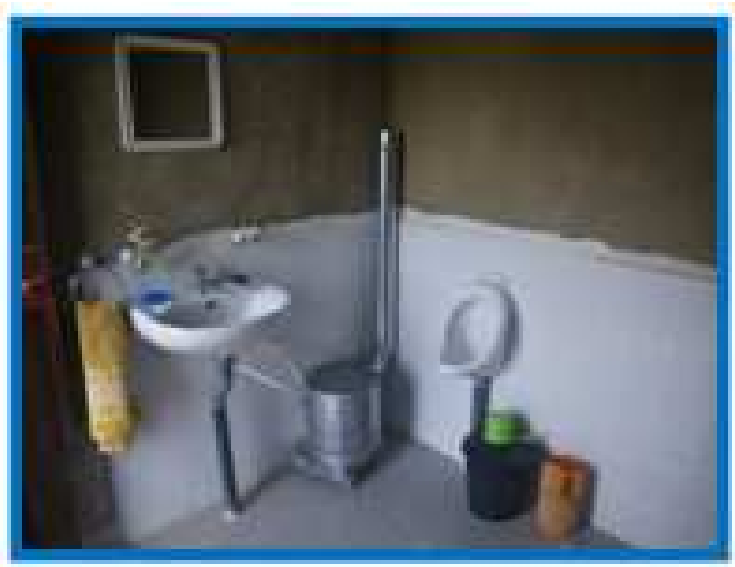

Fig. 3: Wash-hand basin and urinoire

It is composed of two pits functioning alternatively (Fig. 2); a wash-hand basin as well as an urinoire and shower (Fig. 3).

The intimacy of the users is ensured by a superstructure built using bricks and equipped with stairs serving as access to the cabin (Gonidanga, 2004) (Fig. 4). The pits have a depth of 1 meter and are covered by flagstone measuring 2.5 square meters. The pit still to be put into service is protected by a wooden lid. A third pit was also built to be used as shelter for piping collecting the various liquids such as: water of anal cleaning, the urine and gray water coming from wash-hand basin and shower (Fig. 5). The walls are built of bricks.
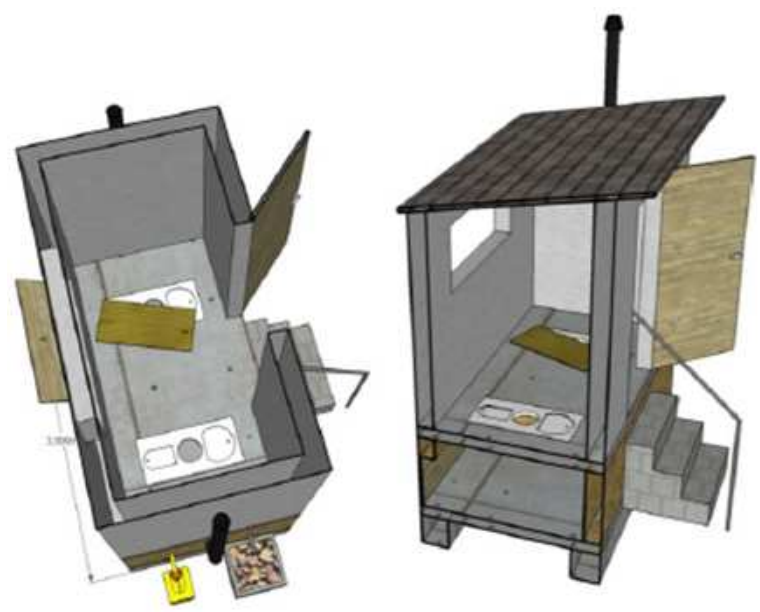

Fig. 4: Schematic view of UDDT superstructures

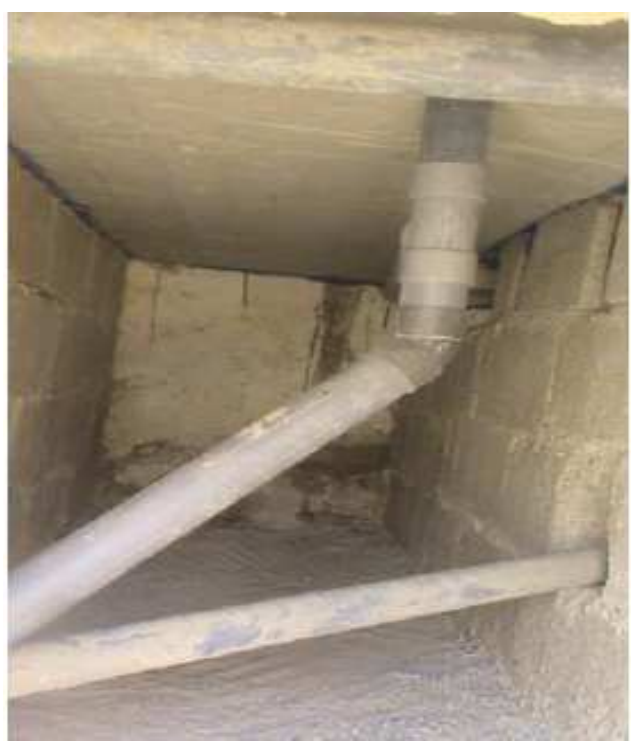

Fig. 5: Pit in construction sheltering various pipings

The fresh excrement will be covered with a mixture of ash as a better additive at destruction of Escherichia coli and Enterococcus spp (Niwagaba et al., 2009). When the pit is full after approximately a year of use, it will be covered by the wooden lid in order that its contents mineralize.

The second pit is then used until it, in turn, is full, at which point the contents of the first pit are prepared for re-use: Its contents are removed so that it continues its decomposition or used immediately as manure (Fig. 2). Since this experiment of realization of an UDDT in December 2009, the population of Dayet Ifrah locality asked for it to be used in their homes. Thus, four other UDDT were built in June 2010 (Fig. 6). 


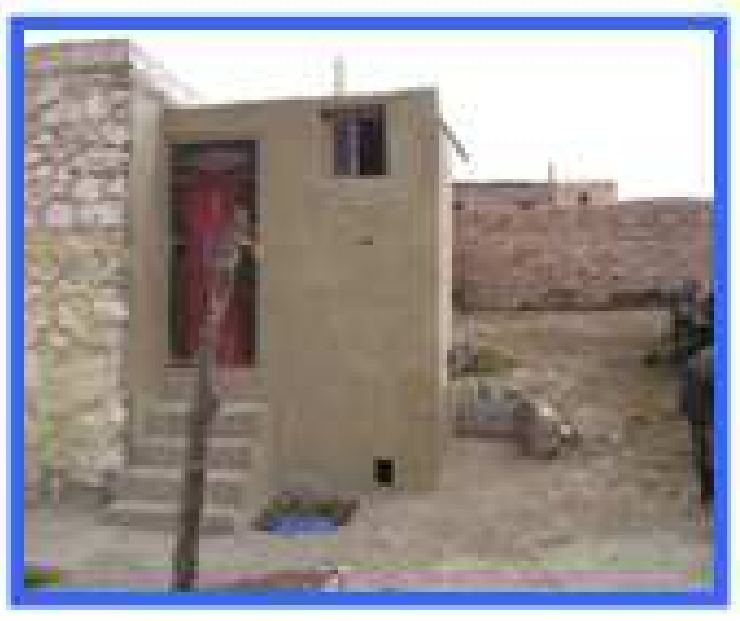

Fig. 6: UDDT built in June 2009

This publication highlights the ecosan promotion strategies and policies for its adoption by the future ecosan users in Morocco. It seeks:

- To document the basic data on acceptability, perception and the incorporation of UDDT in the village of Dayet Ifrah

- To enhance knowledge of selected participants on ecosan facilities, UDDT as a type of toilet, need of safe water and health and hygiene so that we could disseminate information, could aware the communities and empower them to build better sanitation facilities within their household and community

- To develop skills and techniques

- To motivate and empower the community people of different habits, attitudes and believes

\section{MATERIALS AND METHODS}

The study realized in 2009 required a logistic and scientific organization to achieve its goals. The main steps achieved could be summarized as follows:

- Preparation of the questionnaire to be answered by surveyed households

- Determination of the criteria required to select the twenty-four households to be examined, thanks to the local authority and also to Jmâa (Group of the oldest people in Dayet Ifrah as decision makers about the Community affairs). Thus, four households per tribe were chosen by Jmâa (six tribes exist in Dayet Ifrah)

- Interviews with the Cheikh (Local representative of Moroccan authority) to collect general information about the village

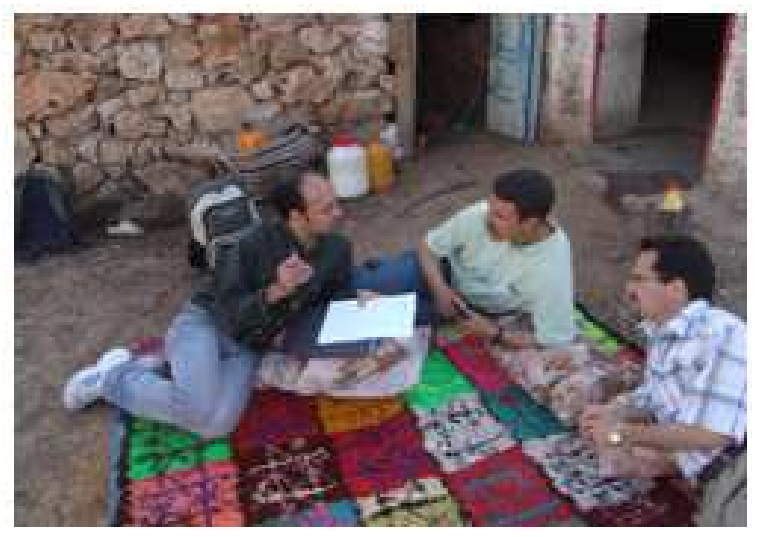

Fig. 7: Interviews with a household head

Table 1: Selection criteria of the UDDT beneficiaries

\begin{tabular}{lc}
\hline Nature of criteria & Weighting (\%) \\
\hline Without toilet & 20 \\
Need of chemical manure & 16 \\
Weak supply water & 1 \\
Availability of site for a toilet & 13 \\
Interest to UDDT & 17 \\
Beneficiaries willingness to & \\
accept future visits from researchers, students & 11 \\
Easy accessibility of the UDDT site for visits & 7 \\
French spoken in the family & 1 \\
possibility to have a garden/field of demonstration & 10 \\
Aptitude for gray water project & 4 \\
Total & $100 \%$ \\
\hline
\end{tabular}

- Visit to schools and mosques and interviews with the individuals responsible for public establishments (teachers, directors,)

- Visit to twenty-four families and interviews with household head or his representative (Fig. 7)

- Localization of the concerned houses with Global Positioning System (GPS)

This investigation was also used to draw up an inventory of the situation of water and wastewater and to select the beneficiaries of the ecosan pilot project in Dayet Ifrah.

The criteria to select UDDT beneficiary people are (Table 1 in appendix):

- Interest of the beneficiary household to take part in an ecosan project

- Participation of beneficiary household in the building work (masonry, earthworks)

- The degree of willingness to take responsibility for maintaining the toilet

- Beneficiaries willingness to accept future visits from researchers, students

- Without toilet 
Am. J. Environ. Sci., 8 (3): 212-219, 2012

- $\quad$ Need for chemical manure

- Weak supply water

- Availability of site for a toilet

According to the criteria mentioned above, twelve (12) families were selected and the choice was presented initially to Jmâa, which approved the proposed list and subsequently to the whole population of the locality.

\section{RESULTS}

Investigation-household: The average size of the households is eight (8) people in the houses without conventional toilets and 6,6 in the houses with toilets. The interest of the households to receive toilets UDDT is: $30 \%$ for the households without toilets against 81 , $8 \%$ for the households having traditional toilets, this is normal because at the beginning of our investigation, the population doesn't know yet ecosan approach.

Females account for $44 \%$ of the surveyed population. The woman of the village remain at the lower end of the alphabetism spectrum. Females account for $13 \%$ of illiterate adults. However, only $38 \%$ of woman benefited from primary education and $3.4 \%$ who benefited from secondary education. This is explained by the fact that the rural females limits themsleves to the first classes of primary school education.

Feder and Slade (1984) affirm that the individuals, in particular the women who have a higher level of education, interpret correctly the information about the innovation of ecosan and its adoption.

All the surveyed population have access to electricity via the national network or the photovoltaic panels. Economically, the selected households do not differ significantly $83 \%$ of the surveyed households have a garden or fields for agricultural demonstration within individual or family fields. Research on agricultural practice conducted in Dayet Ifrah showed that $71 \%$ of households use chemical fertilizer and are in favor of using human excrement as fertilizer for their ground.

Knowledge, preferences and acceptability: We asked the people if they had ever heard about ecosan technology and we discovered that they knew nothing about such technology. It was only in April 2009 that the ecosan approach was introduced for the first time when negotiations with the people and the local authority began.

The future users of the UDDT considered these toilets to be healthiest way to defecate and hoped to have them in their home ever since hearing about them.

The users reported their satisfaction with the new toilets and announced they would recommend this type of toilet to others. They are happy to be the first people to use this kind of toilet in Morocco.
They confirmed that their family had shown an improved comfort since the UDDT was built, previously having defecated in nature even when it snowed or rained. People said, "We do not have to brave the cold. We are sheltered from snow and rain." "Our wives and children are very comfortable."

We asked if beneficiary people could identify the particular aspects of the UDDT they like having.

All the users accepted that which we had proposed to them-UDDT with double pit equipped with shower and wash-hand basins. That which is important for the families is to reserve a part in the toilet for anal cleaning to cleanse oneself after defecating and/or urinating 4 .

In conclusion, all the beneficiary people wished to have an UDDT at home as soon as possible.

Their motivations are focused on the benefits of the ecological sanitation such as: Use of human excrement as manure for agriculture, in particular with the urine, rich in nitrogen and in phosphate (Larsen and Gujer, 1996; Otterpohl, 2002; Vinneras and Jonsson, 2002; Muskolus, 2008; Winker et al.,, 2009). the possibility to increase the agricultural outputs and revenues; the acquisition of a well built toilet near home. The adoption of the approach ecosan in Dayet Ifrah in Morocco is easy to implement.

Workshop of realization of the UDDT in Dayet Ifrah: This workshop was held in Dayet Ifrah from 1427 june 2010. It was an interesting meeting between the representatives of the technical public institutions, municipalities, Universities and researchers. The object is to present the results of the ecosan project in order to provide the basis for the promotion of the approach ecosan in Morocco for the first time.

The objects of the workshop are various. Notably, they include physical achievements, the actions of accompaniment and the sensitizing related to the adoption of the ecosan approach.

Concerning physical achievements, we note constructions by the local masons in four households of the UDDT with double pit and the acquisition of materials. The actions of accompaniment such as the sensitizing, communication and reinforcement of the capacities were also carried out. The advantages relating to the adoption of the ecosan approach in rural areas of Morocco are numerous. They concern the protection of the water resources, the reduction of prevalent diseases related to the bad hygienic practice and the valorization of the nutrients contained in the human excreta. This last advantage would provide Morocco with significant economic gains, if it managed to develop the nutrients contained in the excreta of the whole rural population and this is without taking into 
account the numerous indirect advantages. In addition, for rural areas that still suffer from adequate sanitation, sustainable solutions modelled on decentralized systems are required (Lens et al., 2001).

Use and maintenance practices: The users of the UDDT followed perfectly the maintenance instructions they had been given during the training workshop from 14 to June 27, 2010. Indeed, they all announced that they will add ash to their pits to reduce the odors and, consequently, the number flies normally associated with devices that collect faecal matter (Okalebo et al., 1993). The ash will collected from burning charcoal or wood on charcoal stoves, a practice usually used during food preparation in Dayet Ifrah and in rural areas in Morocco.

\section{DISCUSSION}

We noted that the households who defecate in nature are concerned, at the same time, about having at home less expensive and simpler wastewater sanitation which will encourage the re-use of the hygienized products in agriculture.

Users identification: The Dayet Ifrah village located at $20 \mathrm{~km}$ from the town of Ifrane has a population of one thousand five-hundred (1500). In spite of the proximity of the Ifrane city, this village remains confronted with the consequences of having little infrastructure, such as an insufficient wastewater evacuation infrastructures.

The village has very few toilets, a total of eleven between the twenty-four surveyed households don't have toilets at all. Those existing are called "lost wells" and are not made very well (Fig. 8).

These traditional toilets are abandoned by their users when they are full and replaced by another one dug beside it. The pathogenic bacteria coming from these toilets constitute a major risk of biological pollution of the ground water and are often used as indicators of faecal pollution. The nutrients and pathogenic germs filtrating from these toilets are the cause of contamination of the ground water and the surface water everywhere in the world. Human faecal excreta are the main source of pathogenic organism (Esrey, 1998).

The present research on ecosan in Dayet Ifrah consequently met the approval of the population majority and it was necessary to define clear strategies to identify people who could receive the experimental UDDT.

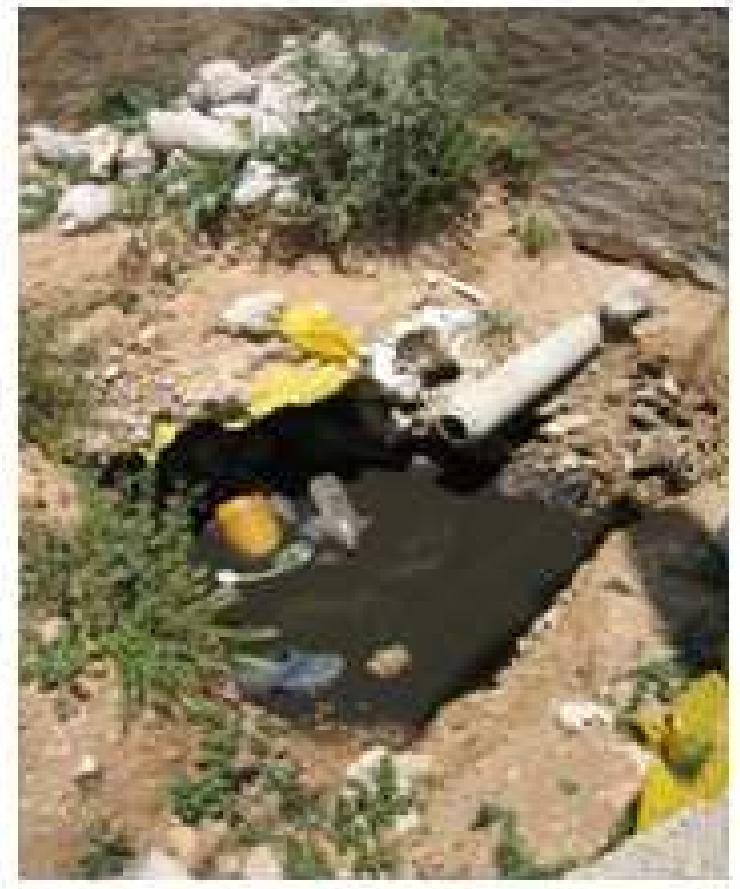

Fig. 8: Lost well used in Dayet Ifrah

The wisdom of the association members and the collaboration of the head of the local authority helped us to choose the future beneficiaries of the UDDT. Thus, it was allocated to this association and to the local authority head to identify the households that will profit from the first UDDT pilot.

Characteristics and profile of the users: The name "user" can be considered as all the members of the profit household of the pilot toilet. "Users" can also be considered as the members of large families including all those who use the toilet during weekly market days.

Our analysis concerns much more the direct users of the toilet, defined as the permanent members of the beneficiary families.

The UDDTs were allotted to four households deprived of wastewater collection and which defecate in nature.

Users reactions: The meetings at the beginning of April 2009 aroused a manifest interest from the population in being able to obtain an ecosan toilet, but in pilot form in order to better appraise the technology, its assets and its strong points, before reaching a conclusion about its generalization.

The advantages related to the use of the hygienized muds in agriculture were timidly accepted because of the ignorance of the new technology. 
The information which we provided was analyzed according to the practices and empirical knowledge of the beneficiaries scattered throughout the world in countries such as Sweden (Rhode et al., 2004; Tidaker et al., 2007), China (Jurga, 2003), India (Sridevi et al., 2009) and South Africa (Mnkeni et al., 2008).

The Chinese have practiced the composting of human and animal excreta for thousands of years and Japan introduced the practice of the human urine recycling into agriculture in the twelfth century. The use of animal excreta in agriculture in Dayet Ifrah draws on the past in order to support the fertilization of the fields.

However, some people asked how the hygienized and developed products will be transported to the fields.

Thus, we propose to wait for the results of the first tests after completing the pilot toilets before arriving at a final decision about whether the products of these toilets constitute good fertilization option for the fields (Kiba, 2005). The manageability of handling the muds and urine, as explained, is a motivating factor and the households are also ready to consume the agricultural produce and market-gardening treaties with the products ecosan.

Justification of the use: The need for or curiosity about having stabilized muds motivates "users" to regularly use the toilets. This use will also be justified because of the high cost of the manure which reaches "users" from remote zones. This cost was estimated at $60 \mathrm{Dh}$ per ton of manure.

The integration of the principles of use: The defecation is a human act which is not usually the subject of discussion or information exchanges, except if the person is attacked by a disease making this act difficult or painful, as is the case with diarrhea or hemorrhoids.

The transmission of the information about the separation of urine from the excreta and about the procedure of addition of ash on the fresh faecal matter seemed at the beginning of the project a little silly to the villages. In Dayet Ifrah and in the majority of the Moroccan rural localities, families are very conservative. A discussion between father and son or between son and brother about human excrement is almost impossible.

The sensitizing day of May 2009 gave its fruit. Indeed, the processes were communicated using imagery in order to get the message across about 6 the separation of the urine and the adequate use of the toilets ecosan (Fig. 9).

These supports facilitated the comprehension of the procedure of use of the toilets and the majority of people affirmed to have all the necessary information about the concept.
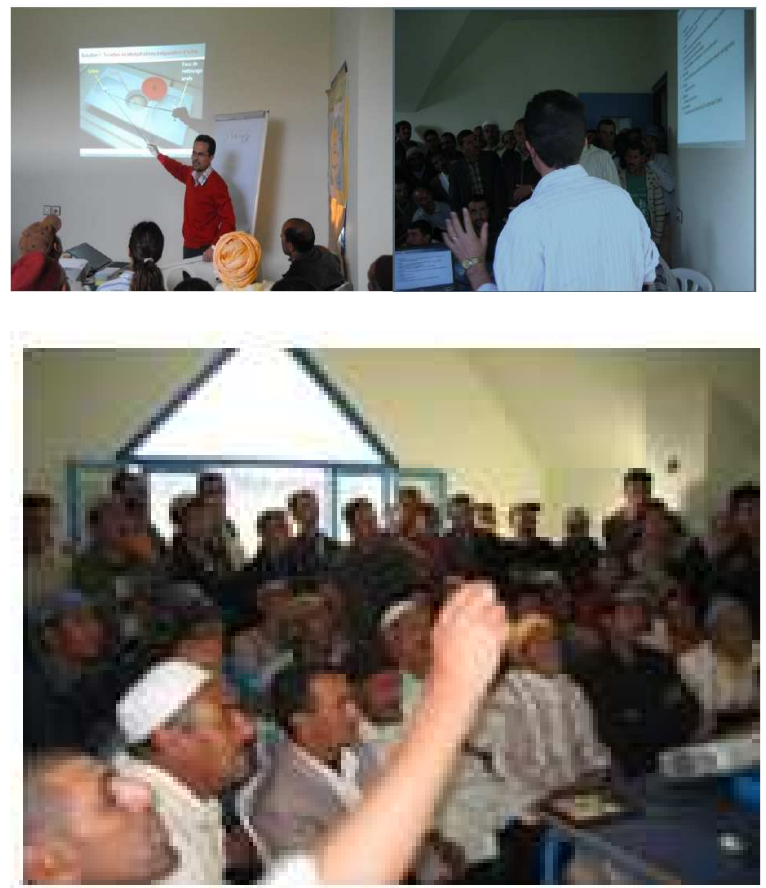

Fig. 9: Meetings of sensitizing of the population

Meetings of recommendation and decision making: In this rural area and at the beneficiary households, there were obvious relationships between UDDT adoption and the agricultural factors and attitudes towards wastewater treatment. They are rural families that defecate in nature. They are thus convinced of association between the property of the UDDT as a technique of collecting and treating wastewater and the conviction to re-use the human excrement (faeces and urine) in agriculture, which would allow on the one hand to protect public health and, on the other, to provide hygienically healthy products for agriculture. For these reasons, the adoption and the promotion of an ecological sanitation in the rural world, where the requirement of fertilizing is strongly expressed, are very welcomed.

In addition, it should be recognized that the ecological sanitation was introduced into the village of Dayet Ifrah and its inhabitants accepted it as a "justified choice". This apparent choice (because in reality, the choice was guided and justified) of the "user" conforms with our promotion strategy of the ecological sanitation in its pilot phase in Dayet Ifrah, knowing that thereafter the users will make their own decisions about the best method for wastewater sanitation. Indeed, thanks to the public sensitizing campaigns during April and May 2009 and the capacity to integrate the various aspects (Technique, Hygiene, Health) in our animation, it was explained that we envisage realizing a first phase of the 
pilot ecosan toilets for families that defecate in nature. This will allow, in a 2nd phase, to evaluate and judge its acceptance by the whole population regarding its replacing existing toilets that are not in conformity with Moroccan law.

Although the households declared that they had not chosen the UDDT as an alternative solution, the choice was made for them and ratified by the local leaders in order to create the request. According to the survey sample, all the users who did not actively choose the UDDT are in favor of the addition of ash and separation of the urine. Those who have not yet profited, did not stop asking us for them during the survey phase and even during the workshop that took place in June 2010. This is a good sign of the success of the generalization of the ecosan approach for the whole population of the village.

Use and maintenance practices: UDDT users were sensitized and educated well on the addition of ash to their pits. For example, $100-500 \mathrm{~mL}$ of ash is enough to cover the fresh faeces after each defecation (Esrey, 2001). The obviousness of the addition of ash to the pits and the use of the specific sites for hand washing are proof of the conformity with advice given to the "users". The conformity with the instruction to add ash is encouraged by real results: The users perceive the addition of ash as a manner of reducing odors and flies.

\section{CONCLUSION}

In this initial phase of ecosan pilot projects planning in Dayet Ifrah, we followed participative methodology SARAR (Self-esteem, Associative Strengths, Resource fulness, Action Planning, Responsability).

This step supplements the tools for traditional planning (feasibility study, technical design). It consists of:

- Sensitizing: A preliminary campaign of sensitizing and dedramatization of a taboo is essential

- Information: It is necessary to awaken the consciences and to arouse the interest of the population on the fertilizing value of manures of human origin; natural, accessible, less expensive and moreover very profitable and advantageous for agricultural produce

- Integration: It is advisable to integrate the technique of the dry toilets with separation of urine in the communal plans of development and sanitation

- Participation: In agreement with the principles of good governance, all the partners must be engaged in decision making and maintenance, in particular the users

- Adequacy: Sanitary technologies must be adapted to the cultural identities. For example, the position chosen for defecating (sitted/squatted), as well as method of cleaning (with or without water), the climate and the available resources

- Acceptability: The sanitation system must be aesthetically irreproachable and compatible with the cultural and social values (way of using a toilet), including equality between the sexes. It is thus necessary to envisage a room of ablutions, equipped with a mirror (in order to allow woman to look at themselves)

- Simplicity: The sanitation system must be sufficiently solid to be easily maintained, taking into account the limits in terms of local technical capacity, the institutional framework and the economic resources

In addition, ecological sanitation in Morocco is in its promising infancy: The users are satisfied at the moment with the ecosan approach to cleanse their wastewater. Our work shows that ecosan can succeed in very poor populations. It is particularly relevant as locomotors of agricultural economics. It creates a strong link between sanitation and agriculture and contributes to food security as well as employment generation with regard to micro and small enterprises operating and managing the sanitation system. Experiences with regard to the use of the toilets and the use of human excreta products in agriculture to this day are promising and encourage the further dissemination of this technology (Meinzinger et al., 2009).

It can be concluded that EcoSan concepts are a way towards a more ecological sound sanitation. There are many different EcoSan concepts available that can be appropriate in different socio-economic and geographical situations. EcoSan concepts are also in accordance with the UN Millenium Development Goals due to their accessibility also to the world's poorest people. There are so many technological options that most social and economic conditions can be met. Creativity is needed to find the appropriate technology and the best way of implementing, operating and financing (Langergraber and Muellegger, 2005).

\section{REFERENCES}

Drangert, J.O., J. Bew and U. Winblad, 1997. Ecological Alternatives in Sanitation. 1st Edn., Swedish International Development Cooperation Agency (Sida), Stockholm, ISBN: 9158675515, pp: 101 . 
Esrey, S.A., I. Andersson, A. Hillers and R. Sawyer, 2001. Closing the loop Ecological Sanitation for food security. Sida, Stockholm, Sweden.

Esrey, S.A., J. Gough, D. Rapaport, R. Sawyer and M. Simpson-Hebert et al., 1998. Ecological sanitation. SIDA, Stockholm.

Feder, G. and R. Slade, 1984. The acquisition of information and the adoption of new technology. Am. J. Agric. Econ., 66: 312-320. DOI: $10.2307 / 1240798$

Gonidanga, S.B., 2004. Contribution to the implementation of the ecological sanitation (Ecosan) in the African context: Study of the hygienisation process of the urine for a healthy use in agriculture. EPFL, pp: 15-20.

Jurga, I., B. Gallinat and H. Mang, 2003. Implementation of a closed-loop sanitation concept in Yang Song township, China. Proceedings of the 2nd International Symposium on Ecological Sanitation, Apr. 7-11, Lubeck, Germany, pp: 843848.

Kiba, D.I., 2005. Agronomic valorization of the human excreta: use of the urine and faeces for the production of the aubergine (Solanus melongena) and of the corn (Zea mays) in the center zone of Burkina Faso. Thesis of Study, IDR/UPB.

Langergraber, G. and E. Muellegger, 2005. Ecological Sanitation-a way to solve global sanitation problems? Environ. Int., 31: 433-444. DOI: 10.1016/j.envint.2004.08.006

Larsen, T.A. and W. Gujer, 1996. Separate management of anthropogenic nutrient solutions (human urine). Water Sci. Technol., 34: 87-94. DOI: 10.1016/0273-1223(96)00560-4

Lens, P., G. Zeeman and G. Lettinga, 2001. Decentralised Sanitation and Reuse: Concepts, Systems and Implementation. 1st Edn., IWA Publishing, London, ISBN: 1900222477, pp: 650.

Meinzinger, F., M. Oldenburg and R. Otterpohl, 2009. No waste, but a resource: Alternative approaches to urban sanitation in Ethiopia. Desalination, 248: 322-329. DOI: 10.1016/j.desal.2008.05.071

Mnkeni, P.N.S., F.R. Kutu, P. Muchaonyerwa and L.M. Austin, 2008. Evaluation of human urine as a source of nutrients for selected vegetables and maize under tunnel house conditions in the Eastern Cape, South Africa. Waste Manage. Res., 26: 132139. DOI: $10.1177 / 0734242$ X07079179

Muskolus, A., 2008. Anthropogenic plant nutrients as fertilizer. Ph.D. Thesis; Department of Crop Sciences, Humboldt-Universitat zu Berlin: Berlin, Germany.
Niwagaba, C., R.N. Kulabako, P. Mugala and H. Jonsson, 2009. Comparing microbial die-off in separately collected faeces with ash and sawdust additives. Waste Manage., 29: 2214-2219. DOI: 10.1016/j.wasman.2009.02.010

Okalebo, J.R., K.W. Gathua and P.L. Woomer, 1993. Laboratory Methods of Soil and Plant Analysis: A Working Manual. 2nd Edn., Tropical Soil Biology and Fertility Programme, Nairobi, ISBN: 9966989218, pp: 88.

Otterpohl, R., 2002. Options for alternative types of sewerage and treatment systems directed to improvement of the overall performance. Water Sci. Technol., 45: 149-158. PMID: 11902466

Rhode, L., A.R. Stintzing and S. Steineck, 2004. Ammonia emissions after application of human urine to a clay soil for barley growth. Nutr. Cycl. Agroecosyst., 68: 191-198. DOI: 10.1023/B:FRES.0000019046.10885.ee

Sridevi, G., C.A. Srinivasamurthy, S. Bhaskar and S. Viswanath, 2009. Evaluation of source separated human urine (ALW) as a source of nutrients for banana cultivation and impact on quality parameter. J. Agric. Biol. Sci., 4: 44-48.

Tchobanoglous, G., H. Theisen and S. Vigil, 1993. Integrated Solid Waste Management: Engineering Principles and Management Issues. 2nd Edn., McGraw-Hill, New York, ISBN: 0070632375, pp: 978.

Tidaker, P., B. Mattsson and H. Jonsson, 2007. Environmental impact of wheat production using human urine and mineral fertilisers-a scenario study. J. Clean Prod., 15: 52-62. DOI: 10.1016/j.jclepro.2005.04.019

Vinneras, B. and H. Jonsson, 2002. The performance and potential of faecal separation and urine diversion to recycle plant nutrients in household wastewater. Bioresour Technol., 84: 275-282. DOI: 10.1016/S0960-8524(02)00054-8

Wang, H. and Y. Nie, 2001. Municipal solid waste characteristics and management in china. Air Waste Manage. Assoc., 51: 250-263. PMID: 11256500

Werner, C., V . Avendano, S. Demsat, I. Eicher and L. Hernandez et al., 2004. Ecosan - Closing the Loop. 1st Edn., GTZ, Germany, ISBN: 3000127917, pp: 1004.

Winker, M., B. Vinneras, A. Muskolus, U. Arnold and J. Clemens, 2009. Fertiliser products from new sanitation systems: Their potential values and risks. Bioresour Technol., 100: 4090-4096. DOI: 10.1016/j.biortech.2009.03.024 